\title{
A procedure for eliminating position habit in preference-aversion tests for ethanol and other fluids'
}

ROBERT D. MYERS AND R. BRUCE HOLMAN

PURDUE UNIVERSITY

A method is described for eliminating the position habit which often arises in experiments designed to determine preference-aversion thresholds for water and a test fluid such as ethanol. A three bottle (i.e., three position) paradigm is employed, but only water and a test fluid are offered to the animal. The third bottle is empty but is rotated every day in a predetermined sequence along with the other two bottles. In preference determinations for different concentrations of ethanol, stable fluid intake functions are obtained.

A simple way to determine preference of one fluid over another is to force an animal to make a choice between two equally accessible fluids. Generally, water and a specific concentration of a test fluid such as ethanol, saccharine or quinine constitute the two choices; the concentration of the test fluid may be varied at daily or other intervals.

The main problem associated with the two-choice method is the occurrence of a position habit (Myers, 1966), whereby the animal always drinks at the same position and disregards the gustatory qualities of the test fluid unless the taste is so noxious that the animal is forced to drink the fluid at the alternative spout in order to survive. Switching the positions of the two drinking bottles every day does not eliminate the position habit. Figure 1 presents typical data for a rat given the choice of water or $10 \%$ ethanol, and shows that the

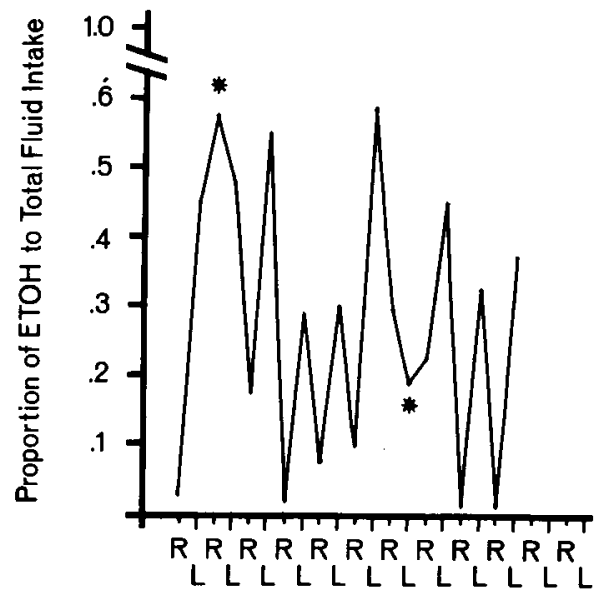

\section{Position of ETOH Bottle on Consecutive Days}

Fig . 1. Pattems of ethanol intake as a function of a position habit in a two-choice test for water or $10 \%$ ethanol. Left-hand spout was preferred. Asterisks denote exceptions to habit. (from T. Cicero, Unpublished M. S. thesis, Purdue University, 1966).
Table 1. Three position schedule for daily placements, in the test chamber, of the "dummy" or empty drinking tube and the two drinking tubes containing a test fluid (ethanol) and water. An ethanol solution was always in drinking tube $A$, tap water in tube $C$, and $B$ was the empty tube.

\begin{tabular}{|c|c|c|c|c|}
\hline Day & $\begin{array}{c}\text { Ethanol } \\
\text { Concentration (\%) }\end{array}$ & Left & Position & Right \\
\hline 1 & 3 & A & B & C \\
\hline 2 & 4 & B & $A$ & C \\
\hline 3 & 5 & A & $C$ & $B$ \\
\hline 4 & 6 & $C$ & A & B \\
\hline 5 & 7 & $c$ & B & $A$ \\
\hline 6 & 8 & B & C & $A$ \\
\hline 7 & 9 & A & B & C \\
\hline 8 & 10 & C & A & B \\
\hline 9 & 11 & A & $C$ & B \\
\hline 10 & 12 & C & B & A \\
\hline 11 & 13 & $A$ & B & $C$ \\
\hline 12 & 14 & B & $c$ & A \\
\hline 13 & 15 & C & A & $\mathrm{B}$ \\
\hline 14 & 16 & $A$ & B & C \\
\hline 15 & 17 & B & C & $A$ \\
\hline 16 & 18 & A & B & $c$ \\
\hline 17 & 19 & C & B & $A$ \\
\hline 18 & 20 & B & A & C \\
\hline
\end{tabular}

pattern of ethanol intake fluctuates simply as a function of the position of the drinking bottle as it was varied from left to right. The difficulty in interpreting position habit data is illustrated by the results of Gillespie \& Lucas (1958) who found that a slight alteration in the placement of a drinking spout eliminated a preference for ethanol in a group of rats which earlier had been termed as having an "alcoholic craving."

Several experimental methods have been developed to overcome the problem of position habit during fluid preference testing. One approach is to add a.third choice by placing a third bottle in the test chamber (Lester \& Greenberg, 1952; Zarrow, Aduss, \& Denison, 1960; Myers, 1964). The difficulty inherent in the three-choice situation, however, is the complexity of matching the properties of each fluid for hedonic values (Young \& Trafton, 1964), caloric properties, and olfactory qualities. Two other methods for eliminating position habit have been based on the rationale that a thirsty animal will investigate and sample available fluids if its drinking is interrupted for brief intervals. In one method the drinking spouts of the test fluids are covered by a sliding plate for $30 \mathrm{sec}$. in each min. so that the total time during which fluids are avail- 


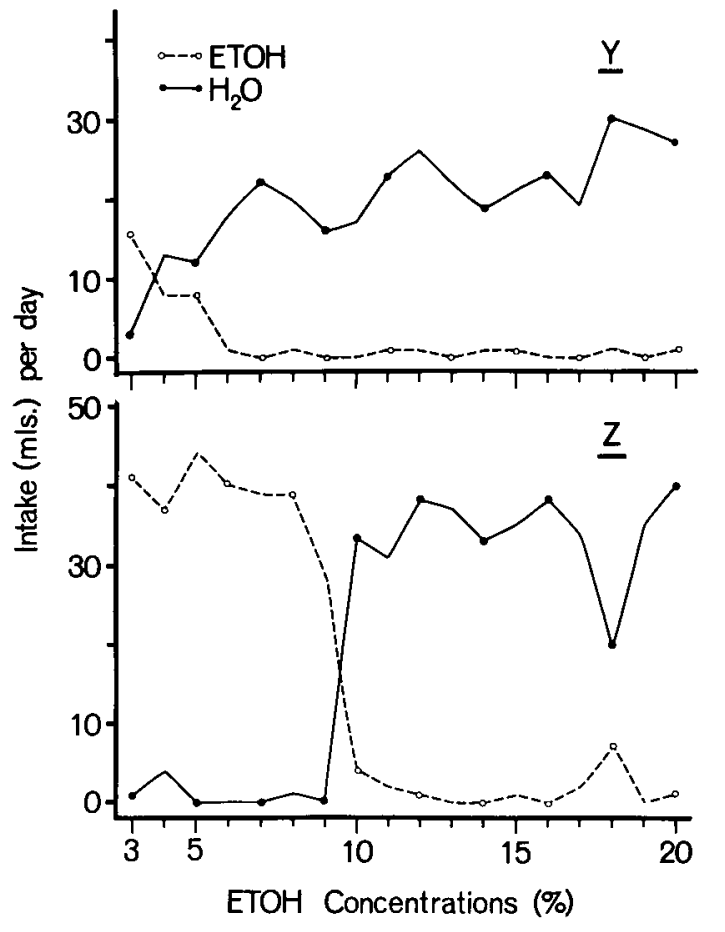

Fig. 2. Fluid intakes in $\mathrm{ml}$, per day for two rats $(Y$ and $Z$ ) given a choice between ad lib. tap water and ethanol (ETOH) solutions, which were increased in concentration in $1 \%$ steps on successive days.

able is reduced by one-half (Myers, 1964). Another method employs a sliding cam, which presents the test fluids for brief periods by moving the drinking bottles in and out of the test chamber (personal communication, Dr. George Collier, 1966).

The method described here retains the advantages of a two-choice situation and at the same time eliminates the necessity of removing the test fluids for even brief intervals.

\section{Method}

The Ss were 28 adult male rats of the Purdue Wistar strain, housed in individual test chambers. Food, water and a solution of ethanol were available throughout the experiment.

Holes were cut in the sides of ordinary test chambers and three Richter (Kimax) tubes were mounted on each chamber. One of the drinking tubes was filled with tap water, the second was filled with a solution of ethanol, and the third served simply as a "dummy" and remained empty. Every day the three bottles were rotated according to a randomly determined sequence for a three-choice situation. Table 1 gives the daily positions, left, middle, or right for the three bottles A, B, and C. Ordinary tap water was available in bottle $\mathrm{C}$, ethanol in increasing concentrations in bottle $\mathrm{A}$, and bottle B was the "dummy." Ethanol solutions were prepared volumetrically with tap water and U.S.P. absolute ethyl alcohol. Fluid intakes were recorded at the same time on every day, and the concentration of ethanol was increased in 1 percent steps on successive days.

\section{Results and Discussion}

Figure 2 presents records for individual Ss, which are typical of those obtained for this group. An almost complete aversion to ethanol, even at low concentrations, was displayed by animal $Y$ (Fig. 2A) which selected water regardless of its position. In spite of the variations in the position of the ethanol tube, preference for ethanol by animal Z (Fig. 2B) persisted throughout the low range of concentrations and terminated with the offering of 9 percent ethanol. In both cases, an unusually stable pattern of fluid selection occurs, quite unlike that seen in Fig. 1 .

It is unclear why the addition of a third position in a choice situation eliminates the position habit, particularly in view of the fact that the third tube contains no fluid. The absence of fluid in one position, however, apparently evokes sufficient exploratory behavior so that fluid at the other positions is sampled. Even if one position would have become preferred, $S$ would sooner or later have made an alternative selection, since fluid is altogether absent on a given day in the sequence.

A preliminary investigation employing this procedure with two rhesus monkeys has showed that preferenceaversion functions can easily be obtained in the primate species without the occurrence of a position habit. Hence, since the procedure retains the advantage of offering two choices to an animal, it could have wide application in experiments involving the factors that govern the ingestion of specific fluids.

\section{References}

Gillespie, R., \& Lucas, C. An unexpected factor affecting the alcohol intake of rats. Canad. J. biochem. Physiol., 1958, 36 . 37-44.

Lester, D., \& Greenberg, L. Nutrition and the etiology of alcoholism. The effect of sucrose, saccharine and fat on the selfselection of ethyl alcohol by rats. Quart. J. Stud. Alcohol., $1952,13,553-560$.

Myers, R. D. Modification of drinking patterns by chronic intracranial chemical infusion. In M. Wayner (Ed.), Thirst. New York: Pergamon Press, 1964. Pp. 553-552.

Myers, R. D. Voluntary alcohol consumption in animals: peripheral and intracerebral factors. Int. J. Psychiat., 1966 (in press).

Young, P. T., \& Trafton, C. Psychophysical studies of taste preference and fluid intake. In M. Wayner (Ed.), Thirst. New York: Pergamon Press, 1964. Pp. 271-285.

Zarrow, M., Aduss, H., \& Denison, M. Failure of the endocrine system to influence alcohol choice in rats. Quart. J. Stud. Alcohol., 1960, 21, 400-413.

\section{Note}

1. This research was supported in part by National Science Foundation Grant GB 387.4 and by a grant from Wallace Laboratories. 